\title{
Update on the German Ross Registry
}

\author{
Hans-Hinrich Sievers, Stephan Ensminger \\ Department of Cardiac and Thoracic Vascular Surgery, University Heart Center Lübeck, University Hospital of Schleswig Holstein, Lübeck, \\ Germany \\ Correspondence to: Stephan Ensminger, MD, DPhil. University Heart Center Lübeck, Ratzeburger Allee 160/Building A, D-23538 Lübeck, Germany. \\ Email: stephan.ensminger@uksh.de.
}

Submitted Aug 12, 2020. Accepted for publication Feb 15, 2021.

doi: 10.21037/acs-2020-rp-154

View this article at: https://dx.doi.org/10.21037/acs-2020-rp-154

The incidence of structural heart disease is increasing worldwide, significantly reducing patient quality of life (QoL) and life expectancy. In most cases, surgical or interventional heart valve replacement is the only therapeutic option and the frequency of these procedures is growing, with 290,000 in 2003 to over 850,000 estimated for 2050 (1). Continuous technical refinement of implanted devices has led to novel mechanical valves with reduced anticoagulation treatment (2); and biological valves with tissue preserved using new anti-calcification strategies (3). Biological valves can be stented/unstented and implanted conventionally with sutures or "sutureless" by rapid deployment (4) or transcatheter techniques. Over the last decade, there has been a clear shift towards the use of bioprostheses documented in the Society of Thoracic Surgeons (STS) national database (5) and German Aortic Valve Registry (GARY) (6). Although both types of valvesmechanical and biological-achieve considerable relief of hemodynamic and clinical burden, they remain prone to prosthesis-related complications such as thromboembolism, lifelong anticoagulation and bleeding, unphysiological hemodynamics, reoperation, endocarditis and reduced life expectancy. For young and middle-aged patients, an ideal valve substitute remains lacking.

To overcome these shortcomings, alternatives like the recently introduced Ozaki-procedure (7) and the Ross operation are available (8).

In theory, the pulmonary autograft provides several features required for an ideal valve substitute. It is autologous, consists of live cells and shares major developmental, geometrical, histological and morphogenic aspects with the aortic valve (AV). Principally, there are three different "Ross" techniques: the free-standing root replacement, advantageously preserving the geometry of the autograft but needing protective measures against dilatation; the more complex subcoronary technique, leaving the aortic root in place, thus preventing dilatation; and the root inclusion technique, necessitating reimplantation of the coronary ostia. The right ventricular outflow tract (RVOT) is preferably reconstructed by using a pulmonary homograft. This operative method never gained widespread application and led to different recommendations in international guidelines, mainly due to the complexity of the operation and that two valves are put at risk in a patient with single valve disease. Heterogenous institutional results also contributed to the procedure's reduced popularity. An essential requirement for an optimal Ross operation is a dedicated program (center of excellence), lifelong patient surveillance, critically analyzing results to further refine surgical technique and characterization of patients who benefit most from this procedure. This was our initial motivation, when the German Ross Registry was started in 2002 as a real-world data analysis. Data were collected from 1988 to 2001 retrospectively and prospectively from 2002 aiming at follow-up $>90 \%$. Today, more than 2,500 patients are included from ten centers in three countries (Austria, Czech Republic and Germany), with the registry entering its third decade. The most striking result is the longterm survival in young and middle-aged patients does not seem to differ from the normal population-at least for a period of 25 years. This may be related to the excellent, in most cases physiological, hemodynamics and the low rate of thromboembolism and hemorrhage, but also the selection of patients. Nevertheless, we must be mindful that there is a slight yet insignificant decline in survival of Ross patients beginning in the second decade and a marginal 
impairment of long-term autograft and homograft function $(9,10)$. Unpublished registry data suggest that patients with preoperatively decreased left ventricular ejection fraction experienced reduced long-term survival, indicating that adequate time for the operation prior to non-reversible myocardial damage is advantageous. Furthermore, the impairment of autograft function seemed to be related to pre-existing $\mathrm{AV}$ insufficiency, since a higher degree of decreased autograft function was observed compared to patients with AV stenosis (10). Therefore, these patients need careful surveillance. From our experience, the prevention of hypertension has a beneficial effect on autograft function and more liberal antibiotic treatment in case of infection protects against homograft endocarditis. The rate of re-intervention was lower than reported for bioprostheses but higher compared to mechanical valves. However, there was some increased risk of reoperation during the last decade. Whether this can be reduced by neutralizing the risk factors for autograft reoperation, namely aortic regurgitation and large annulus diameters, remains to be evaluated. Interestingly, the surgical technique itself was no longer an independently related predictor for autograft reoperation. From a surgical point of view, a reduction and fixation of the annulus to $24-28 \mathrm{~mm}$ in relation to body surface area is a significant issue for excellent autograft function. Issues also arose with the implantation of the autograft into the aortic root without distortion in an annular horizontal plane, sometimes difficult in bicuspid AV, especially in those with a raphe between the left and right coronary leaflets (Sievers Type 1, L-R). Whether a repair of an insufficient AV or an Ozaki procedure as an alternative to the Ross procedure provides similar results remains to be established. A repair or Ozaki operation first, with the Ross procedure to follow in the case of failure, may be an interesting, but as yet unproven strategy for special indications. For RVOT reconstruction, the homograft provides the best results compared to bioprostheses. Hopefully, new generation decellularized homografts may increase its durability by reducing antigenicity and therefore deterioration. Transcatheter techniques for replacement of failed homografts are increasingly applied, reducing the need for reoperations.

Other invaluable advantages of the Ross procedure include the low rate of thromboembolism, hemorrhage, valve thrombosis, stroke and endocarditis, as well as freedom from anticoagulation. Collectively, these aspects enhance QoL, allow unrestricted activities and normal pregnancy. Despite these achievements, many questions remain, particularly if these registry data are useful for comparison with data from patients with mechanical valves who are generally recommended for this age group. There is increasing evidence that the Ross procedure reveals significant advantages compared to mechanical valve replacement with respect to long-term survival, risk of thromboembolism, bleeding, stroke and QoL.

\section{Conclusions}

After twenty-five years, the Ross Registry data indicate that the Ross procedure holds its promise regarding excellent survival, low valve-related morbidity and high QoL, warranting a more liberal use in experienced centers especially for young and middle-aged patients with AV disease. Nevertheless, there is risk of reoperation and late decline in valve performance in some patients, indicating that the Ross procedure does not entirely match normal AV conditions. For further quality improvement, a high degree of standardization (e.g., special sizers) would be desirable. This can be achieved by facilitating the technique, establishing standardized training curricula, making proctoring with certification for the procedure possible, refining preoperative imaging for in-vitro simulation and using artificial intelligence software to steer perfect surgery-essential for optimal long-term function. For more durable RVOT reconstruction, new techniques such as tissue engineering with scaffolds from extracellular or bioabsorbable matrices, bio-3D printing, computational modelling, and the use of bio-nanotechnology may be helpful.

\section{Acknowledgments}

Funding: None.

\section{Footnote}

Conflicts of Interest: The authors have no conflicts of interest to declare.

Open Access Statement: This is an Open Access article distributed in accordance with the Creative Commons Attribution-NonCommercial-NoDerivs 4.0 International License (CC BY-NC-ND 4.0), which permits the noncommercial replication and distribution of the article with the strict proviso that no changes or edits are made and the original work is properly cited (including links to both the 
formal publication through the relevant DOI and the license). See: https://creativecommons.org/licenses/by-nc-nd/4.0/.

\section{References}

1. Yacoub MH, Takkenberg JJ. Will heart valve tissue engineering change the world? Nat Clin Pract Cardiovasc Med 2005;2:60-1.

2. Puskas JD, Gerdisch M, Nichols D, et al. Anticoagulation and Antiplatelet Strategies After On-X Mechanical Aortic Valve Replacement. J Am Coll Cardiol 2018;71:2717-26.

3. Puskas JD, Bavaria JE, Svensson LG, et al. The COMMENCE trial: 2-year outcomes with an aortic bioprosthesis with RESILIA tissue. Eur J Cardiothorac Surg 2017;52:432-9.

4. D'Onofrio A, Salizzoni S, Filippini C, et al. Surgical aortic valve replacement with new-generation bioprostheses: Sutureless versus rapid-deployment. J Thorac Cardiovasc Surg 2020;159:432-442.e1.

5. Tam DY, Rocha RV, Wijeysundera HC, et al. Surgical valve selection in the era of transcatheter aortic valve replacement in the Society of Thoracic Surgeons Database.
J Thorac Cardiovasc Surg 2020;159:416-427.e8.

6. Fujita B, Ensminger S, Bauer T, et al. Trends in practice and outcomes from 2011 to 2015 for surgical aortic valve replacement: an update from the German Aortic Valve Registry on 42776 patients. Eur J Cardiothorac Surg 2018;53:552-9.

7. Ozaki S, Kawase I, Yamashita H, et al. Midterm outcomes after aortic valve neocuspidization with glutaraldehydetreated autologous pericardium. J Thorac Cardiovasc Surg 2018;155:2379-87.

8. Ross DN. Replacement of aortic and mitral valves with a pulmonary autograft. Lancet 1967;2:956-8.

9. Sievers HH, Stierle U, Charitos EI, et al. A multicentre evaluation of the autograft procedure for young patients undergoing aortic valve replacement: update on the German Ross Registry†. Eur J Cardiothorac Surg 2016;49:212-8.

10. Sievers HH, Stierle U, Petersen M, et al. Valve performance classification in 630 subcoronary Ross patients over 22 years. J Thorac Cardiovasc Surg 2018;156:79-86.e2.
Cite this article as: Sievers HH, Ensminger S. Update on the German Ross Registry. Ann Cardiothorac Surg 2021;10(4):515517. doi: 10.21037/acs-2020-rp-154 